\title{
AVALIAÇÃO TEMPORAL DA QUALIDADE DA ÁGUA E DESOXIGENAÇÃO NO RIO CATOLÉ GRANDE, BAHIA
}

Natália Andrade Silvão - naty_andrade18@hotmail.com

Universidade Estadual do Sudoeste da Bahia

Lídia Raiza Sousa Lima Chaves Trindade - lidiaraiza@ hotmail.com

Universidade Estadual do Sudoeste da Bahia

Romário Oliveira de Santana - engenheiro.romario@ hotmail.com

Universidade Estadual do Sudoeste da Bahia

Alison Silva dos Santos - alisonss@outlook.com

Universidade Estadual do Sudoeste da Bahia 


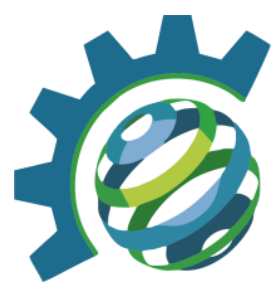

\section{RESUMO}

O objetivo deste trabalho foi avaliar a variação temporal de variáveis limnológicas do rio Catolé Grande em um ponto a montante do município de Itapetinga-BA, e quantificar e avaliar temporalmente o coeficiente de desoxigenação (K1) e a demanda última de oxigênio $\left(\mathrm{L}_{0}\right)$ no mesmo rio em um ponto situado a jusante do mesmo município. As variáveis limnológicas oxigênio dissolvido, condutividade elétrica, $\mathrm{pH}$, turbidez e temperatura foram obtidas na base de dados da Agência Nacional das Águas (ANA) código 53780000. O K1 foi obtido utilizando-se o mesmo procedimento para a demanda bioquímica de oxigênio, por períodos de $0,1,2,3,4,5,7,9,11,13,15,17,19$ e 21 dias enquanto o coeficiente de reaeração foi obtido substituindo-se os dados de entrada na equação proposta por StreeterPhelps. Analisando os resultados obtidos para as variáveis limnológicas conclui-se que o maior valor de turbidez foi observado no período de menor incidência de chuvas; as demais variáveis condutividade elétrica, potencial hidrogeniônico e oxigênio dissolvido, apresentaram relação direta com a incidência de chuvas; a temperatura da água foi menor nos períodos mais frios do ano e que apresentaram maior regime pluviométrico. Os valores estimados de $\mathrm{K}_{1}$, apresentaram variação temporal, com maior valor no período de maior incidência de chuvas. A classificação proposta por von Sperling (1996) em relação ao $\mathrm{K}_{1}$ variou entre rios com efluentes secundários e águas limpas ou efluentes secundários. Os valores de demanda última de oxigênio tiveram relação direta com os valores do coeficiente de desoxigenação.

Palavras-chave: poluição aquática, recursos hídricos, variáveis de qualidade.

\section{INTRODUÇÃO/OBJETIVO}

As diversas atividades exercidas pelo homem na bacia hidrográfica causam impactos aos ecossistemas aquáticos, como rios e riachos, tornando o seu controle um dos grandes desafios da gestão dos recursos hídricos (TEODORO et al., 2013). Atividades como irrigação, desmatamento, urbanização, lançamentos pontuais: domésticos e industriais; causam impactos negativos na qualidade e quantidade das águas, tornando-as indisponível para as necessidades humanas (TERNUS, et al., 2011; GONÇALVES et al., 2012).

O conceito de qualidade da água não é limitado apenas ao conceito de pureza, mas sim às características das suas variáveis limnológicas físicas, químicas e biológicas (CORDEIRO et al., 2016). O monitoramento limnológico fornece subsídios relevantes para a caracterização espaço-temporal de corpos d'água em bacias hidrográficas, denunciando as condições de uso do solo e as atividades antropogênicas desenvolvidas em uma bacia, como lançamento de efluentes domésticos e industriais no corpo hídrico (MAROTTA et al., 2008).

Em geral, as consequências de um determinado poluente dependem das suas concentrações, do tipo de corpo d'água que o recebe e dos usos da água. Para a definição de limites de concentrações de cada poluente a Política Nacional de Recursos Hídricos, implementada pela Lei 9.433/97 tem como uma de suas diretrizes basais a introdução à gestão sistemática dos recursos hídricos, que determina a associação dos aspectos de quantidade e qualidade da água. A Resolução Conama 357/2005 define as concentrações dos despejos para cada classe elucidando as suas limitações e estabelecendo as condições e padrões de lançamentos de efluentes, sejam eles domésticos ou industriais (BRASIL, 1997; BRASIL, 2005). 


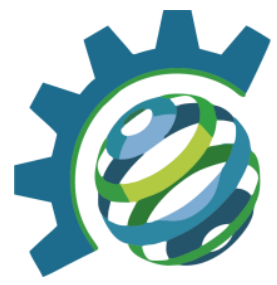

Para auxiliar na gestão, controle e proteção dos corpos hídricos os modelos matemáticos são utilizados como ferramentas que possibilitam a análise e o prognóstico dos mesmos, permitindo a simulação dos processos de autodepuração do rio (GONÇALVES et al., 2012). O fenômeno da autodepuração envolve processos biológicos, físicos, químicos, que permitem que o corpo hídrico possa recuperar o seu estado natural ao longo de certa distância de determinado trecho do rio (VON SPERLING, 2007; DEMARS \& MANSON, 2013).

O modelo de Streeter Phelps foi precursor de modelos numéricos de qualidade de água, sendo ainda largamente utilizado, servindo de suporte a outros modelos mais sofisticados que se sucederam. Este é constituído, de forma genérica, por duas equações diferenciais ordinárias: uma modela consumo de OD devido à oxidação da matéria orgânica, sendo basicamente governado pelo coeficiente de desoxigenação, $\mathrm{K}_{1}$, que varia de acordo com a composição e a concentração do material orgânico na água residuária; e outra, o fluxo de oxigênio proveniente da dinâmica da reaeração atmosférica (K2) (BEZERRA et al., 2008; BARROS et al., 2011; CUNHA et al., 2011; HAIDER et al, 2013).

Diante do exposto, o objetivo deste trabalho foi avaliar a variação temporal de variáveis limnológicas do rio Catolé Grande em um ponto a montante do município de Itapetinga-BA, e quantificar e avaliar temporalmente o coeficiente de desoxigenação $\left(\mathrm{K}_{1}\right)$ e a demanda última de oxigênio $\left(\mathrm{L}_{0}\right)$ no mesmo rio em um ponto situado a jusante do município

\section{METODOLOGIA}

O presente estudo foi realizado na bacia hidrográfica do Rio Catolé Grande pertencente à bacia hidrográfica do Rio Pardo (Figura 1). Esta bacia, considerando o sistema de projeção Universal Transversa de Mercator (UTM), está contida na zona 24, entre os

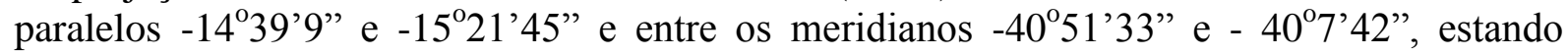
totalmente localizada na região sudoeste da Bahia. O Rio Catolé Grande nasce no município de Vitória da Conquista e drena para a calha do Rio Pardo no sentido Nordeste-Sudeste, com sua seção de controle a jusante da cidade de Itapetinga ((LIMA e PINTO, 2011). Possui uma área de $3.128 \mathrm{~km}^{2}$ composta pelos municípios de Vitória da Conquista, Itambé, Barra do Choça, Planalto, Caatiba, Nova Canaã e Itapetinga.

A paisagem natural da bacia do Rio Catolé Grande foi quase que totalmente substituída por pastagens que recobrem quase $75 \%$ das terras dos municípios que compõem a bacia (LIMA \& PINTO, 2011). São compostas de pastagens plantadas, principalmente com o capim braquiária (Brachiaria decumbens Stapf) e capim colonião (Panicum maximum), pastagens naturais (formadas a partir da derrubada das matas, plantio de culturas anuais e o posterior rebroto de espécies herbáceo/arbustivas) e áreas plantadas com forrageiras para corte (LIMA \& PINTO, 2011). Somado a este fator a rede coletora de esgoto do município despeja todo o efluente doméstico diretamente no rio, sem nenhum tratamento, aumentando a poluição dos recursos hídricos da região.

As variáveis limnológicas oxigênio dissolvido, condutividade elétrica, $\mathrm{pH}$, turbidez e temperatura foram obtidas na base de dados da Agência Nacional das Águas (ANA) código 53780000, referente ao município de Itapetinga-BA, local onde será realizado o presente estudo. A coleta das amostras foi realizada a montante do município, estando as amostras isentas do lançamento de efluentes domésticos e agroindustriais. 

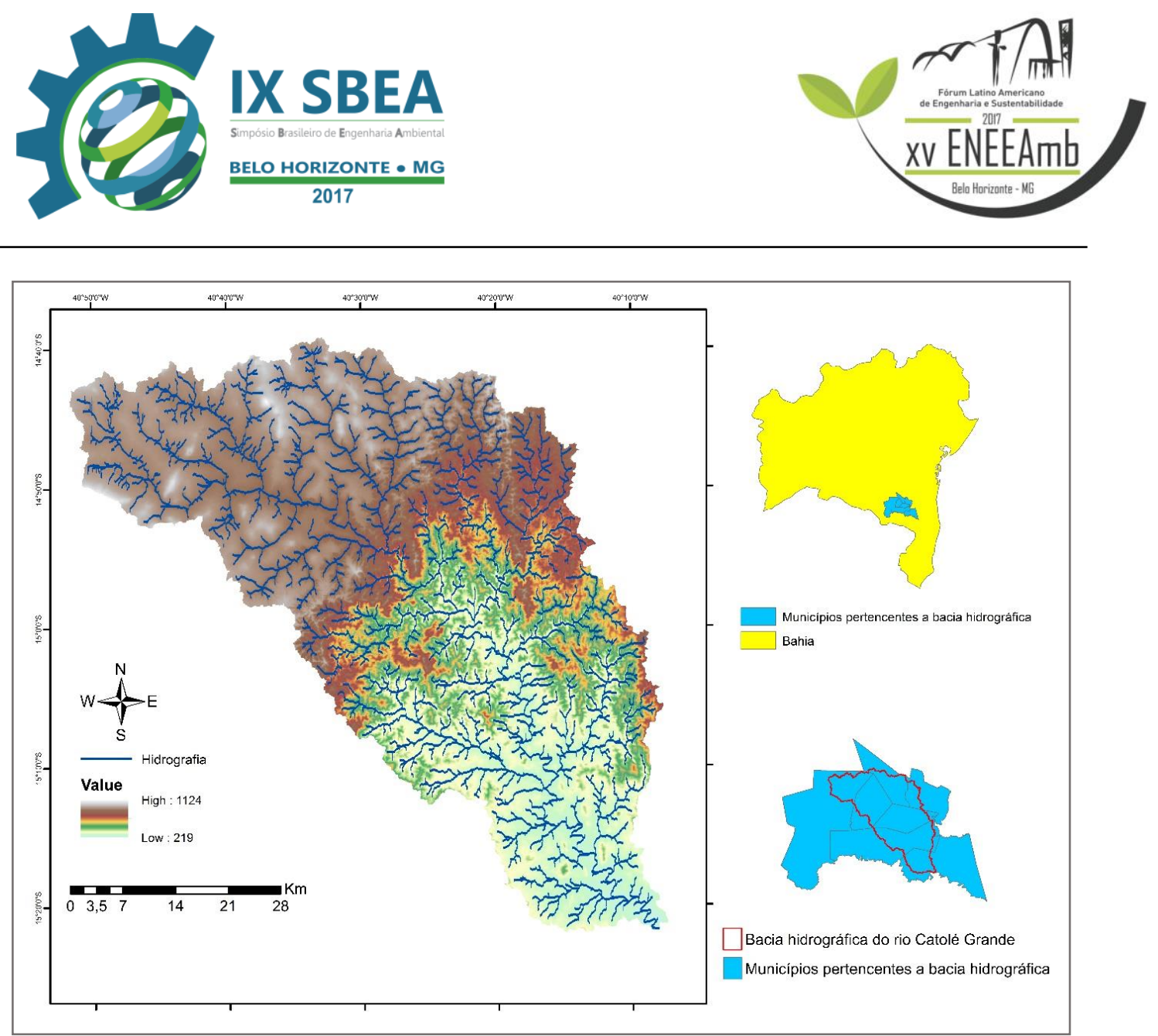

Figura 1. Bacia hidrográfica do rio Catolé Grande.

As amostras de água para determinação da demanda última de oxigênio foram coletadas na seção transversal do rio Catolé em um ponto localizado a jusante do perímetro urbano do município de Itapetinga-BA (-15'16'9.97" e $\left.-40^{\circ} 13^{\prime} 3.09 "\right)$, por ser um ponto representativo de toda carga de efluentes domésticos e agroindústrias (laticínios e frigoríficos) do município. A coleta foi realizada seguindo metodologia expressa pela ANA (BRASIL, 2011). Anteriormente a coleta, foi realizada o procedimento de ambientação do frasco ao líquido coletado. Após a coleta, as amostras de água foram acondicionadas em caixas de isopor e transportadas imediatamente ao Laboratório de Solos da Universidade Estadual do Sudoeste da Bahia, onde foram realizadas as análises de DBO.

A determinação da demanda bioquímica de oxigênio (DBO) foi realizada pelo método da NBR 12614/1992, o qual recomenda que uma amostra de água destilada ou deionizada seja incubada no período de 24 horas para que ocorra a saturação de oxigênio na amostra pela diferença de temperatura, sendo em seguida preparada uma solução nutriente. Após a obtenção da solução nutriente foi realizado o preparo das amostras, sendo a primeira apenas com a solução nutriente e as outras $13 \mathrm{com} 5 \mathrm{~mL}$ da amostra do rio Catolé Grande mais a solução nutriente.

O coeficiente de desoxigenação $\left(\mathrm{K}_{1}\right)$ foi obtido em laboratório utilizando-se amostras de água coletada do Rio Catolé, e que foram submetidas à incubação, sob temperatura de $20^{\circ} \mathrm{C}$, utilizando-se o mesmo procedimento para obtenção da DBO por períodos de $0,1,2,3$, 4, 5, 7, 9, 11, 13, 15, 17, 19 e 21 dias. Posteriormente foram ajustados os parâmetros das equações de regressão não linear, proposta por Streeter Phelps (1925), de forma a se obter os parâmetros de $\mathrm{K}_{1}$ e da demanda última de oxigênio (Lo), conforme Equação 1.

em que:

$$
y=L_{0}\left(1-e^{\left(-K_{1} T\right)}\right) \quad \text { Equação } 1
$$

$\mathrm{y}=\mathrm{DBO}$ exercida em um tempo $\mathrm{t}\left(\mathrm{mg} \mathrm{L}^{-1}\right)$; 

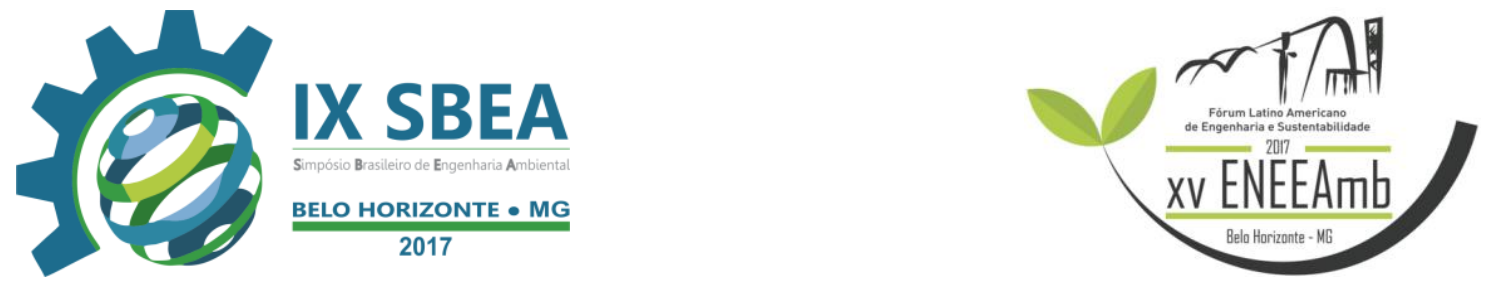

Lo=demanda última de oxigênio que representa a DBO total ao final da estabilização $\left(\mathrm{mg} \mathrm{L}^{-}\right.$ $\left.{ }^{1}\right)$;

$\mathrm{K}_{1}=$ coeficiente de desoxigenação $\left(\operatorname{dia}^{-1}\right)$;

$\mathrm{t}=$ tempo $(\mathrm{d})$.

Os dados de precipitação correspondentes ao período das coletas foram obtidos a partir da Estação Meteorológica Automática - A446 do Instituto Nacional de Meteorologia (INMET), situada no município de Itapetinga-BA. Na Figura 2 estão apresentadas as lâminas diárias precipitada, obtidas pela estação meteorológica do município, correspondentes aos 30 dias que antecederam cada coleta.

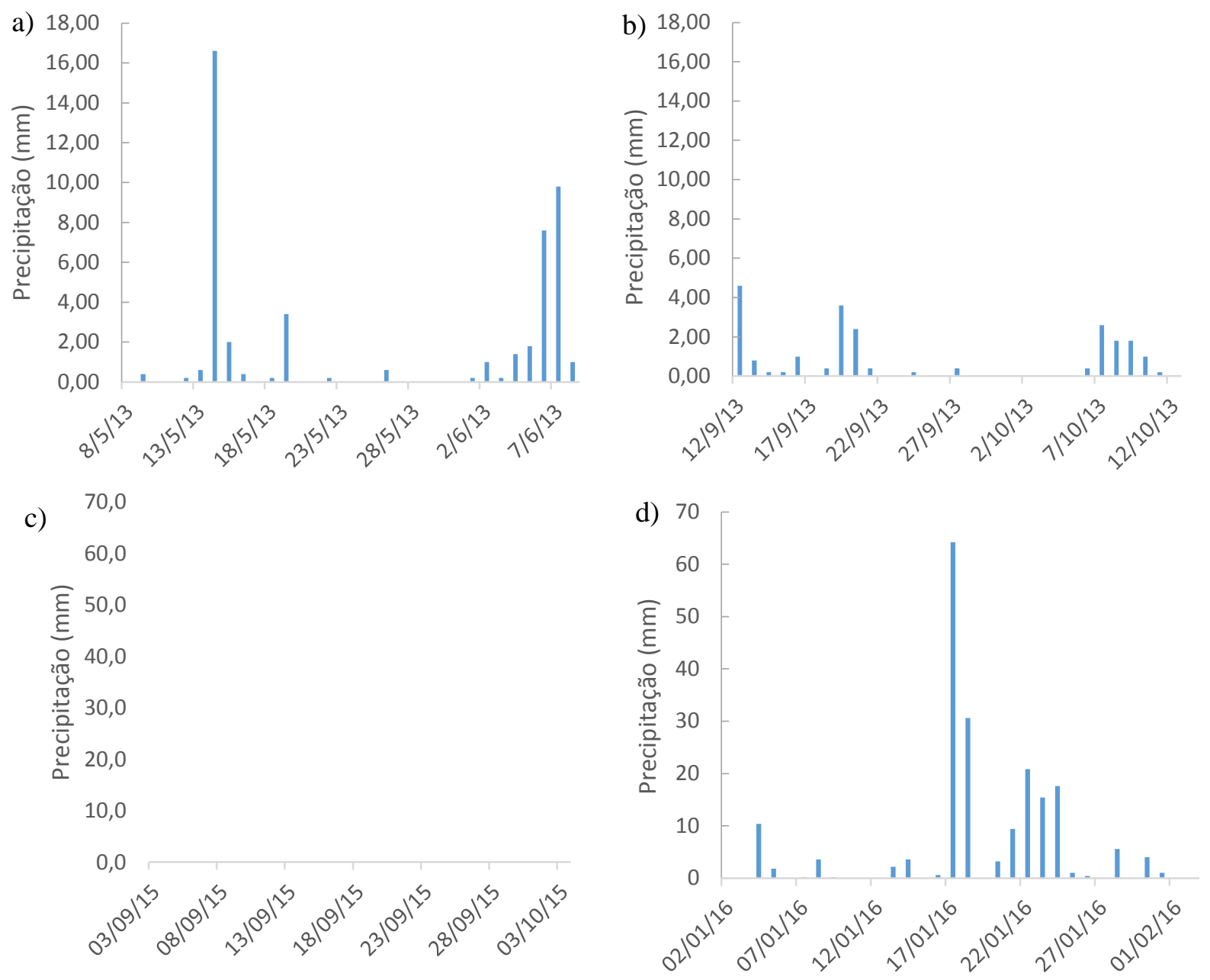

Figura 2: Dados diários de precipitação correspondentes aos períodos de estudo, obtidas pela Estação Meteorológica Automática - A446 do Instituto Nacional de Meteorologia (INMET), situada no município de Itapetinga-BA. As figuras 2a e $2 \mathrm{~b}$ são referentes as variáveis limnológicas e abrangem o período de 07/06/2013 a 08/06/2016 e 12/09/2013 a 12/10/2013, respectivamente. As figuras 2c e 2d são referentes à demanda última de oxigênio $\left(\mathrm{L}_{0}\right)$ e ao coeficiente de desoxigenação $\left(\mathrm{K}_{1}\right)$ e abrangem o período de 03/09/2015 a 03/10/2015 e 02/01/2016 a 02/02/2016, respectivamente.

\section{RESULTADOS E DISCUSSÃO}

\subsection{Variação temporal das variáveis limnológicas}




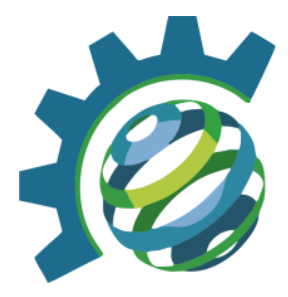

Na Tabela 1 estão apresentados os valores das variáveis limnológicas para o Rio Catolé Grande nos dois períodos de estudo.

Tabela 1: valores das variáveis limnológicas para os dois períodos de estudo em um ponto situado antes do perímetro urbano do município de Itapetinga-BA

\begin{tabular}{ccc}
\hline PARÂMETROS & $\begin{array}{c}\text { Coleta 1 } \\
\mathbf{0 8 / 0 6 / 2 0 1 3}\end{array}$ & $\begin{array}{c}\text { Coleta 2 } \\
\mathbf{1 2 / 1 0 / 2 0 1 3}\end{array}$ \\
\hline Turbidez $(\mathrm{NTU})$ & 7,9 & 15,6 \\
Condutividade elétrica $\left(\mu \mathrm{S} \mathrm{cm}^{-1}\right)$ & 137 & 127,3 \\
Potencial hidrogeniônico & 7,91 & 7,61 \\
Oxigênio dissolvido $\left(\mathrm{mg} \mathrm{L}^{-1}\right)$ & 8,62 & 6,99 \\
Temperatura $\left({ }^{\circ} \mathrm{C}\right)$ & 23,2 & 29 \\
\hline
\end{tabular}

A turbidez na água é causada pela presença de matéria orgânica e inorgânica em suspensão e a variação em rios ocorre, principalmente, em decorrência de chuvas. Entretanto, esta apresentou correlação inversa com o regime pluviométrico. Foi observado que no período de menor incidência de chuvas (Figura 2b) ocorreu maior valor de turbidez (15,6 NTU). Isso indica que a capacidade de diluição do material em suspensão foi maior no período de maior incidência de chuvas (Figura 2a), apresentando menores valores de turbidez (7,9 NTU), o que não era esperado. Além disso, como a coleta 2 foi realizada em um período de maior temperatura do ar, pode ter ocasionado diminuição do volume de água no leito do rio e consequentemente contribuído para uma maior concentração de material em suspensão.

O limite de turbidez estabelecido pela Resolução CONAMA 357/2005 para rios de Classe 2 é de até 100 NTU, o qual não foi excedido em nenhuma das coletas. Rocha et al. (2010), monitorando a qualidade da água do mesmo rio, em um período de maio a setembro de 2009, observaram uma variação de turbidez entre 7 e 24 NTU. Esta variação, segundo os próprios autores, pode ser devido às precipitações ocorridas, que contribuíram para o aumento desta variável, alocando ao rio maiores concentrações de partículas. Silva et al. (2008), avaliando a qualidade da água do Rio Purus, encontrou menores valores de turbidez em períodos de maior incidência de chuvas, corroborando com os resultados encontrados neste estudo.

A condutividade elétrica apresentou maior valor no período de maior incidência de chuvas $(137 \mu \mathrm{S} \mathrm{cm}-1)$, o que indica uma maior quantidade de sais neste período. As chuvas e a diminuição dos mecanismos de retenção (baixa permeabilidade, compactação do solo e desmatamento) ocasionados por atividades antrópicas, contribuem para que nutrientes possam ser escoados para o leito dos rios aumentando a concentração de elementos dissolvidos.

A resolução CONAMA 357/05 não estabelece valor para condutividade elétrica, sendo utilizado como parâmetro de qualidade, o valor estabelecido pela CETESB (2014) de $100 \mu \mathrm{S} / \mathrm{cm}$, sendo que ambientes com condutividade elétrica acima desse valor podem ser considerados impactados. Entretanto, os sais presentes na água, não estão relacionados apenas a fatores externos, como a disposição de sedimentos no leito do rio, como também podem ter origem na dissolução ou intemperização das rochas e solos.

Rocha et al (2010) encontrou valores de condutividade para o rio Catolé Grande que variaram entre $160 \mu \mathrm{S} \mathrm{cm}-1$, período de maior incidência de chuva, $100 \mu \mathrm{S} \mathrm{cm}-1$ no período de menor incidência de chuvas, comportamento similar ao deste trabalho. 


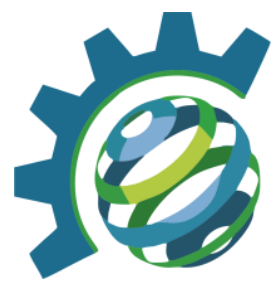

Observando-se os valores para o potencial hidrogeniônico nota-se que a amplitude média dos valores observados no Rio Catolé Grande foi pequena variando entre 7,91 e 7,61, indicando valores aceitáveis segundo a Resolução CONAMA 357/05 a qual estipula valores de $\mathrm{pH}$ entre 6 e 9 para todas as classes de qualidade de água doce. Sendo assim, todos os valores encontrados neste estudo estão dentro da faixa de normalidade. Barreto et al. (2014) analisando a qualidade da água no mesmo rio, em um período compreendido entre janeiro e novembro de 2011, observaram uma variação do $\mathrm{pH}$ entre 6,23 e 7,16.

A concentração de oxigênio dissolvido (OD) foi maior no período de maior precipitação (8,62 mg L-1) (Figura 2a). Com as chuvas há um aumento nos valores velocidade e consequentemente de turbulências das águas, o que oferece melhores condições de mistura e favorece a incorporação de OD na água. Além disso, foi observado menores valores de temperatura da água $(23,20 \mathrm{C})$ o que favorece a solubilidade de oxigênio dissolvido.

Os valores de OD para as duas coletas estão acima dos limites estabelecidos pelas Resolução CONAMA 357/05, que estabelece limites mínimo de $5 \mathrm{mg}$ L-1 para corpos hídricos classe II. Os valores de OD estão dentro da faixa de normalidade, considerando que o ponto de coleta está situado a montante do perímetro urbano, não recebendo cargas de efluentes domésticos e agroindustriais deste.

Os valores de temperatura tiveram variação em acordo com as condições climáticas, apresentando menor valor $\left(23,2^{0} \mathrm{C}\right)$ em estações frias do ano e maior valor $\left(29^{0} \mathrm{C}\right)$ nas estações mais quentes.

\subsection{Variação temporal da demanda última de oxigênio $\left(L_{0}\right)$ e coeficiente de desoxigenação $\left(K_{1}\right)$}

$\mathrm{Na}$ Tabela 2 estão apresentados os resultados da demanda última de oxigênio última $\left(\mathrm{L}_{0}\right)$ e do coeficiente de desoxigenação $\left(\mathrm{K}_{1}\right)$ para o Rio Catolé Grande.

Tabela 1 - Valores da demanda última de oxigênio $\left(\mathrm{L}_{0}\right)$ e do coeficiente de desoxigenação $\left(\mathrm{K}_{1}\right)$ para o Rio Catolé Grande em um ponto situado imediatamente após o perímetro urbano

\begin{tabular}{ccc}
\hline PARÂMETROS & Coleta 1 & Coleta 2 \\
& $\mathbf{0 3 / 1 0 / 2 0 1 5}$ & $\mathbf{1 2 / 0 2 / 2 0 1 6}$ \\
\hline DBOu & $19,7098 \mathrm{mg} \mathrm{L}^{-1}$ & $34,1538 \mathrm{mg} \mathrm{L}^{-1}$ \\
$\mathrm{~K}_{1}$ & $0,1014 \mathrm{~d}^{-1}$ & $0,2323 \mathrm{~d}^{-1}$
\end{tabular}

Os valores obtidos para os coeficientes de desoxigenação $\left(\mathrm{K}_{1}\right)$, nas duas coletas realizadas demonstraram, de maneira geral, variação temporal, com maior coeficiente $(0,2323$ $\mathrm{d}^{-1}$ ) em períodos de maior incidência de chuvas (Figura $2 \mathrm{~d}$ ). Maior $\mathrm{K}_{1}$ indica maior velocidade na oxidação de matéria orgânica, que pode variar de acordo com a composição e a concentração de material orgânico de água residuária (VON SPERLING, 1996). Em períodos chuvosos há a ocorrência de escoamento superficial, o que aumenta o transporte de sedimentos para o leito do rio que por consequência aumenta os valores de $K_{1}$. Além disso, nestes períodos a velocidade das águas provoca ressuspensão de sedimentos, o que provoca aumento da matéria orgânica dissolvida e particulada no leito do rio.

No município de Itapetinga-BA a principal atividade econômica é a agropecuária. Entretanto, a falta de manejo causa impactos sobre o solo trazendo como consequência baixa permeabilidade, alta compactação e erosão do solo que em períodos chuvosos carreia 


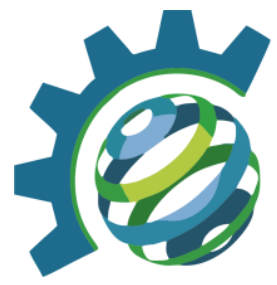

sedimentos para o corpo hídrico. Além disso, a retirada de trechos de matas ciliares facilita a entrada de sedimentos no rio.

Comparando os valores de $\mathrm{K}_{1}$ apresentado na Tabela 2 com os valores genéricos apresentados por Von Sperling (1996) para vários tipos de efluentes e águas, pode-se classificar a água do rio Catolé Grande como água limpa ou efluente secundário para a coleta 1 e como efluente secundário para a coleta 2.

Brandalero et al. (2010) observaram relação direta de K4 com períodos sazonais, apresentando maiores valores do coeficiente em períodos de maior incidência de chuvas, corroborando com resultados apresentados neste estudo.

Barros et al. (2008), avaliando a reoxigenação do rio Turvo Sujo obteve valor de $\mathrm{K}_{1}$ de $0,19 \mathrm{dia}^{-1}$, valor dentro do intervalo encontrado neste trabalho $\left(0,1014\right.$ a $\left.0,2323 \mathrm{~d}^{-1}\right)$, sendo a classificação dentro da faixa de valores de rios com águas limpas ou efluente secundário segundo a classificação proposta por Von Sperling (1996).

Observou-se uma relação direta entre os valores de demanda última de oxigênio $\left(\mathrm{L}_{0}\right)$ e os valores de $\mathrm{K}_{1}$. Esta relação indica que em períodos de maior precipitação o consumo de material orgânico é maior em decorrência da maior velocidade de assimilação deste material. O aumento da velocidade das águas, observado em períodos em que há ocorrência de chuvas, aumenta a incorporação de oxigênio dissolvido, que é fator limitante no processo de decomposição de matéria orgânica. Além disso, o principal tipo de efluente lançado no rio Catolé Grande é de natureza orgânica, que se caracteriza como efluente de mais rápida assimilação quando comparado a efluentes industriais.

Teodoro (2013) afirma que o coeficiente de desoxigenação é diretamente proporcional à quantidade de matéria orgânica, portanto os resultados encontrados estão dentro do esperado. Um estudo realizado pelo mesmo autor aponta valores para $\mathrm{K}_{1}$ e $\mathrm{L}_{0}$ variando entre 0,10 - 0,14 e 1,60 - 3,70 respectivamente. Barros et al. (2011), avaliando a reoxigenação e desoxigenação do rio Turvo Sujo obteve $\mathrm{K}_{1}$ e demanda última de oxigênio de $0,19 \mathrm{~d}^{-1}$ e $40,09 \mathrm{mg} \mathrm{L}^{-1}$.

\section{CONCLUSÕES}

Conclui-se que o maior valor de turbidez foi observado no período de menor incidência de chuvas. Todos os valores de turbidez estão dentro dos limites estabelecidos pela Resolução CONAMA 357/05 para águas doce classe II. As demais variáveis limnológicas condutividade elétrica, potencial hidrogeniônico e oxigênio dissolvido, apresentaram relação direta com a incidência de chuvas. As variáveis potencial hidrogeniônico e oxigênio dissolvido apresentaram valores dentro dos limites estabelecidos pela Resolução CONAMA 357/05 nas duas coletas. A variável condutividade elétrica apresentou valores superiores ao estabelecido pela CETESB, que define que ambientes com condutividade acima de 100 $\mu \mathrm{S} / \mathrm{cm}$ é característico de ambientes impactados. A temperatura da água foi menor nos períodos mais frios do ano e que apresentaram maior regime pluviométrico.

$\mathrm{O}$ coeficiente de desoxigenação apresentou maior valor na coleta $2\left(0,2323 \mathrm{~d}^{-1}\right)$, que foi marcada por maior incidência de chuvas. Pela classificação proposta por Von Sperling (1996) o rio Catolé Grande varia entre rios com efluentes secundários e águas limpas ou efluentes secundários. Os valores de demanda última de oxigênio tiveram relação direta com os valores do coeficiente de desoxigenação. 

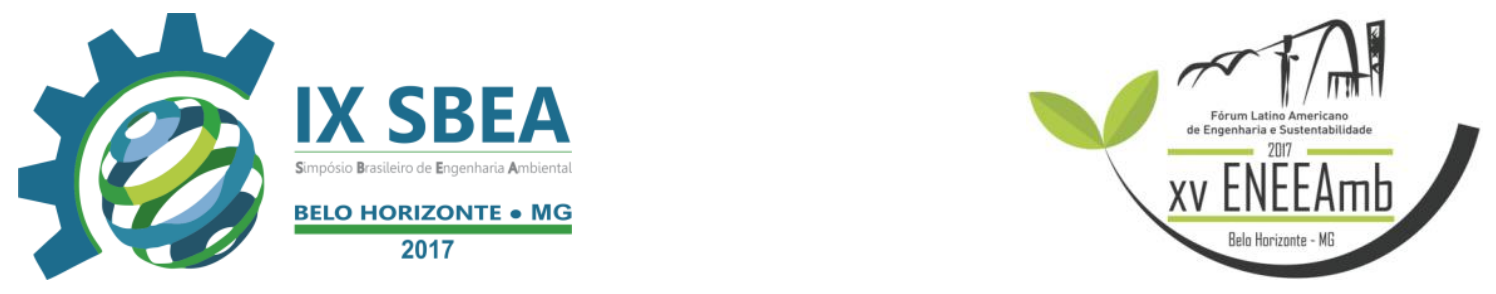

\section{REFERÊNCIAS BIBLIOGRÁFICAS}

BARRETO, L. V.; FRAGA, M. S.; BARROS, F. M.; ROCHA, F. A.; AMORIM, J. S.; DE CARVALHO, S. R.; BONOMO, P.; DA SILVA, D. P. Relação entre vazão e qualidade da água em uma seção de rio. Revista Ambiente \& Água, v. 9, p. 118-129, 2014.

BARROS, F. M.; MARTINEZ, M. A.; MATOS, A. T.; ROCHA, F. A.; SILVA, D. P. Reoxigenação e desoxigenação no rio Turvo Sujo. Enciclopédia Biosfera, v. 7, p. 1-5, 2011.

BEZERRA, I. S. O.; MENDONÇA, L. A. R.; FRISCHKORN, H. Autodepuração de cursos d'água: um programa de modelagem Streeter Phelps com calibração automática e correção de anaerobiose. Revista Escola de Minas v. 61 n. 2 Ouro Preto abr./jun. 2008.

BRANDELERO, S. M.; SIQUEIRA, E. Q.; LIMA, A. C. B. Desoxigenação em água superficial de ambiente lótico. Revista Ambiente \& Agua, Taubaté, v. 5, n. 1, p. 163-171, 2010.

BRASIL, 1997. Política Nacional dos Recursos Hídricos. Lei $\mathrm{n}^{\circ}$ 9.433, de 8 de janeiro de 1997. Institui a Política Nacional de Recursos Hídricos, cria o Sistema Nacional de Gerenciamento de Recursos Hídricos, regulamenta o inciso XIX do art. 21 da Constituição Federal, e altera o art. $^{\circ}$ da Lei $n^{\circ}$ 8.001, de 13 de março de 1990, que modificou a Lei $\mathbf{n}^{0}$ 7.990, de 28 de dezembro de 1989. Diário Oficial da República Federativa do Brasil, Brasília, 1997.

BRASIL 2005. Resolução CONAMA (Conselho Nacional de Meio Ambiente). Resolução n. ${ }^{\circ}$ 357, de 17 de Março de 2005. Dispõe sobre a classificação dos corpos de água e diretrizes ambientais para o seu enquadramento, bem como estabelece as condições e padrões de lançamento de efluentes, e dá outras providências. Diário Oficial da República Federativa do Brasil, Brasília, 2005.

BRASIL, 2011. Resolução ANA (Agência Nacional das Águas). Resolução n.o 274, de 03 de Outubro de 2011. Estabelece procedimentos padronizados para a coleta e preservação das amostras de águas superficiais para fins de monitoramento da qualidade dos recursos hídricos, no âmbito do Programa Nacional de Avaliação da Qualidade das Águas. Diário Oficial da República Federativa do Brasil, Brasília, 2011.

CUNHA, A. C.; BRITO, D. C.; CUNHA, H. F. A; SCHULZ, H. E. Dam Effect on Stream Reaeration Evaluated with QUAL2KW Model: Case Study of the Araguari River, Amazon Region, Amapá State/Brazil. In: BILLIBIO, C.; HENSEL, O.; SELBACH, J. Sustainable Water Management in the Tropics and Subtropics - And Case Studies in Brazil. Fundação Universidade Federal do Pampa, Jaguarão/RS, p. 697. 2011.

CORDEIRO, G. G.; GUEDES, N. M.; KISAKA, T. B.; NARDOTO, G. B. Avaliação rápida da integridade ecológica em riachos urbanos na bacia do rio Corumbá no Centro-Oeste do Brasil. Revista Ambiente \& Água, vol. 11 n. 3 Taubaté - Julho / Setembro 2016

DEMARS, B. O. L.; MANSON, J. R. Temperature dependence of stream aeration coefficients and the effect of water turbulence: a critical review. Water Research, v. 47, p. 1$15,2013$.

GONÇALVES, J. C. S. I.; SARDINHA, D. S.; SOUZA, A. D. G.; DIBIAZI, A. L. B.; GODOY, L. H.; CONCEIÇÃO, F. T. Avaliação espaço-temporal da qualidade da água e 

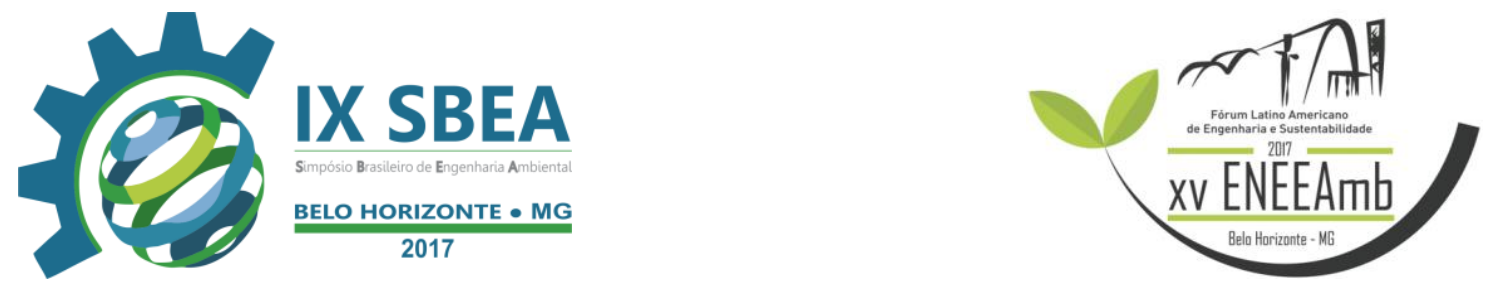

simulação de autodepuração na bacia hidrográfica do córrego São Simão, SP. Revista Ambiente \& Água, Taubaté, v. 7, n. 3, p. 141-154, 2012.

HAIDER, H.; ALI, W.; HAYDAR, S. Evaluation of various relationships of reaeration rate coefficient for modeling dissolved oxygen in a river with extreme flow variations in Pakistan. Hydrological Processes, v. 27, p. 3949-3963, 2013.

LIMA, E.M., PINTO; J.E.S. Bacia do rio catolé, Bahia - brasil: bases geoambientais e socioeconômicas para a gestão da água e do solo. Revista Geográfica de América Central Número Especial. EGAL, 2011- Costa Rica II Semestre 2011 pp. 1-11.

MAROTTA, H.; SANTOS, R. O.; ENRICH-PRAST, A. Monitoramento limnológico: um instrumento para a conservação dos recursos hídricos no planejamento e na gestão urbanoambientais. Revista Ambiente \& Sociedade, Campinas, v. 11, n. 1, p. 67-79, 2008.

ROCHA, F. A.; BARROS, F. M. Variáveis de qualidade de água influenciadas pelo tipo e época de amostragem, no rio Catolé-BA. Revista Enciclopédia Biosfera, v. 6, p. 1-6, 2010.

SILVA, A. E. P.; ANGELIS, C. F.; MACHADO, L. A. T.; WAICHAMAN, A. V. Influência da precipitação na qualidade da água do Rio Purus. Revista Acta Amazonica. v. 38 p.733 742. 2008.

STREETER, H.W.; PHELPS, E.B. A study of the pollution and natural purification of the Ohio river. U.S. Public Health Serv. Bull 146, Washington: Public Health Service, 1925.

TEODORO, A.; IDE, C. N.; RIBEIRO, M. L.; BROCH, S. A. O.; SILVA, J. B. da. Implementação do conceito Capacidade de Diluiçãode Efluentes no modelo de qualidade da água QUAL-UFMG: estudo de caso no Rio Taquarizinho (MS). Revista Engenharia Sanitária e Ambiental. vol.18 no.3, Rio de Janeiro jul./set. 2013.

TERNUS, R.Z., SOUZA-FRANCO, G.M., ANSELMINI, M.E.K., MOCELLIN, D.J.C. \& DAL MAGRO, JACIR. 2011. Influence of urbanisation on water quality in the basin of the upper Uruguay River in western Santa Catarina, Brazil. Revista Acta Limnol. Bras. 23:189199.

VON-SPERLING, M. Princípios de tratamento biológico de águas residuárias: introdução e qualidade das águas e do tratamento de esgotos. 2. ed. Belo Horizonte: FMG, 1996. 